\title{
Wpływ procesu spawania na mikrostrukturę ferrytycznych stali nierdzewnych
}

\author{
Influence of welding process \\ on microstructure of ferritic stainless steels
}

\section{Streszczenie}

W pracy przedstawiono wyniki badań metalograficznych wykonane na złączu spawanym ze stali X10CrAlSi13. Badaniom zostało poddane złącze P1, w którym nie zastosowano podgrzewania wstępnego. Obserwacji mikrostruktury po spawaniu poddane zostały obszary materiału rodzimego, SWC oraz SWC w pobliżu linii wtopienia, ze względu na użycie austenitycznego materiału dodatkowego do spawania klasy 18-8-6 (Cr-Ni-Mn). W artykule przedstawiono również makrostrukturę złącza oraz przeprowadzono badania twardości. Dodatkowo przeprowadzono ocenę wpływu procesu spawania na mikrostrukturę stali X10CrAISi13. Wskazano również kierunki dalszych badań nad ferrytycznymi stalami nierdzewnymi.

Słowa kluczowe: ferrytyczne stale nierdzewne; mikrostruktura; korozja

\begin{abstract}
The paper presents influence of welding process on microstructure of $\mathrm{X} 10 \mathrm{CrAlSi} 3$ steel welded joints. Research concentrates on microstructure of parent material, HAZ and HAZ approximate to fusion line due to usage of austenitic 18-8-6 (Cr-Ni-Mn) welding consumable. Article also presents macrography and hardness tests of welded joint. Additionally influence of welding process on X10CrAlSi13 steel was evaluated. Finally study provides guidance for further research on ferritic stainless steels.
\end{abstract}

Keywords: ferritic stainless steels; microstructure; corrosion.

\section{Wstęp}

Chromowe stale ferrytyczne są stopami żelaza z Cr o zawartości w przedziale $10,5 \div 30 \%$ o strukturze krystalicznej RPC. Zazwyczaj ferrytyczne stale nierdzewne zawierają dodatki stopowe ferrytotwórcze Al, Ti, Nb, Mo, Si, V, W mające na celu poprawę właściwości chemicznych i fizycznych oraz stabilizację struktury ferrytycznej do temperatury otoczenia. Ze względu na skłonność do korozji międzykrystalicznej stali tej klasy ich podstawową cechą jest małą zawartość węgla. Stale ferrytyczne odporne na korozję nawet o bardzo małej zawartości C mają znacznie gorszą ciągliwość niż stale austenityczne, ponadto przechodzą w stan kruchy w wyższych temperaturach. Właściwości wytrzymałościowe stali również są obniżone (ze względu na zawartość C) i ich $R_{e}$ oscyluje w granicach $210 \div 480 \mathrm{MPa}[1 \div 3]$.

Chromowa stal ferrytyczna X10CrAISi13 należy do grupy stali żaroodopornych ijest przeznaczona na żaroodporne części kotłów (m.in. brodawki pomiarowe, elementy mocujące i szeregujące przegrzewacze) oraz pieców przemysłowych, komór próżniowych itp. Maksymalna temperatura pracy - żaroodporność tej stali wynosi $850^{\circ} \mathrm{C}$. Stal ta jest odporna na działanie gazów zawierających związki siarki i gazy redukujące, słabo odporna na działanie atmosfery nawęglającej, azotującej i węgloazotującej.

Spawalność ferrytycznych stali nierdzewnych jest ograniczona ze względu na ograniczoną plastyczność, wrażliwość na przegrzanie, czyli znaczny rozrost ziarna pod wpływem wysokiej temperatury (struktura jednofazowa). Dodatkowym problemem są procesy wydzieleniowe pod wpływem procesu spawania prowadzące do powstawania węglików prowadzące do nadmiernej kruchości złącza spawanego

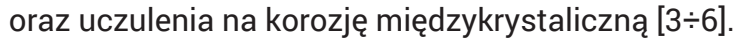

W związku z powyższym prawidłowe opracowanie technologii spawania, charakteryzujące się ograniczoną energią liniową w celu minimalizacji wprowadzonego ciepła do złącza spawanego ma istotne znaczenie na końcowe właściwości i strukturę złącza spawanego.

Mgr inż. Maciej Woszek - Doosan Babcock Energy Polska Sp. z o.o.; dr hab. inż. Jacek Słania, Prof. PCz - Politechnika Częstochowska; dr hab. inż. Grzegorz Golański, Prof. PCz - Politechnika Częstochowska.

Autor korespondencyjny/Corresponding author. maciejwoszek@gmail.com 


\begin{tabular}{|c|c|c|c|c|c|c|c|}
\hline \multicolumn{8}{|c|}{ Zawartość pierwiastków, \% masy } \\
\hline X10CrAlSi13 & C & Si & Mn & $\mathbf{P}$ & s & $\mathrm{Cr}$ & Al \\
\hline $\begin{array}{l}\text { Skład chemiczny } \\
\text { badanej stali }\end{array}$ & 0,065 & 0,94 & 0,84 & 0,021 & 0,001 & 12,56 & 0,93 \\
\hline $\begin{array}{c}\text { Wymagana zawartość } \\
\text { pierwiastków według } \\
\text { PN-EN } 10095\end{array}$ & $\max 0,12$ & $0,50 \div 1,0$ & $\max 1,00$ & $\max 0,040$ & $\max 0,015$ & $12,00 \div 14,00$ & $0,70 \div 1,20$ \\
\hline
\end{tabular}

Tablica II. Właściwości mechaniczne stali X10CrAlSi13 [1] Table II. Mechanical properties of X10CrAlSi13 steel [1]

\begin{tabular}{|c|c|c|c|c|}
\hline & $\begin{array}{c}\mathbf{R}_{\mathbf{p} 0,2,} \\
\mathbf{M P a}\end{array}$ & $\begin{array}{c}\mathbf{R}_{\mathbf{m}}, \\
\mathbf{M P a}\end{array}$ & $\begin{array}{c}\text { Twar- } \\
\text { dość, } \\
\mathbf{H V 1 0}\end{array}$ & $\begin{array}{c}\text { Wydłuże- } \\
\text { nie A, } \\
\%\end{array}$ \\
\hline $\begin{array}{c}\text { Właściwości stali } \\
\text { w stanie dostawy }\end{array}$ & 437 & 591 & 192 & 15 \\
\hline $\begin{array}{c}\text { Wymagane } \\
\text { właściwości } \\
\text { wg PN-EN 10095 }\end{array}$ & min. 250 & $450 \div 650$ & $\max 250$ & $\operatorname{min.15}$ \\
\hline
\end{tabular}

\section{Materiał do badań}

Materiałem do badań były płyty wykonane ze stali X10CrAlSi13 o wymiarach 10x200x125 mm. Badany materiał dostarczony był w stanie wyżarzonym. Skład chemiczny oraz właściwości mechaniczne materiału rodzimego w stanie dostawy zestawiono w tablicach I i II [1].

\section{Technologia spawania}

Złącze doczołowe blach wykonano w pozycji PF bez podgrzewania wstępnego i temperaturą międzyściegową wynoszącą $150{ }^{\circ} \mathrm{C}$ (złącze oznaczono jako P1). P1 nie zostało poddane obróbce cieplnej po spawaniu. Charakterystyka stali ferrytycznych wrażliwych na przegrzanie i doprowadzane ciepło do złącza oraz jednofazowa struktura ferrytyczną nie wskazuje na słuszność zaleceń literatury $[2,4,5]$ podgrzewania wstępnego i obróbki cieplnej po spawaniu stali tej klasy.

Złącza wykonano metodą 111 ze względu na dużą wszechstronność metody oraz częste wykonywanie złączy tego typu w warunkach montażowych, gdzie wykorzystanie gazu osłonowego może być problematyczne. Warto zauważyć, że w przypadku spawania metodą 111 tej klasy złączy musi być zapewniony dostęp do złącza z dwóch stron ze względu na konieczności wycięcia/wyszlifowania grani i wykonaniu drugiego lica lub zastosowanie spawania na podkładce z osłoną grani gazem obojętnym.

Materiałem dodatkowym wykorzystanym w obu technologiach była elektroda E 188 Mn B 22 (Böhler FOX A7). Spoiwa austenityczne są zalecane do spawania chromowych stali ferrytycznych ze względu na bardzo dobre właściwości plastyczne, udarność stopiwa oraz podwyższenie odporności na korozję spoiny. Elektroda FOX A7 w pełni spełnia wymagania stawiane materiałowi rodzimemu. Skład chemiczny oraz właściwości mechaniczne elektrody FOX A7 zostały przedstawione w tablicy III.

\section{Pomiar twardości}

Dla złącza P1 maksymalna twardość nie przekracza wartości 225 HV10 dla pomiaru od strony grani. Twardość materiału rodzimego (MR) i strefy wpływu ciepła (SWC) była na poziomie nie przekraczającym 190 HV10. Według normy materiałowej PN-EN 10095 materiał rodzimy X10CrAISi13 powinien wykazywać twardość poniżej 250 HV10. Ten warunek został spełniony dla SWC i spoiny złącza P1. Warto jednak zauważyć, iż norma dotycząca kwalifikacji technologii spawania PN-EN ISO 15614-1 nie stawia wymagań twardości chromowym stalom ferrytycznym (grupa materiałowa 7 według ISO TR 15608). W związku z powyższym złącze P1 spełnia wszelkie wymagania stawiane twardości przez normy dotyczące stali X10CrAlSi13. Wyniki pomiarów twardości przedstawia rysunek 1.

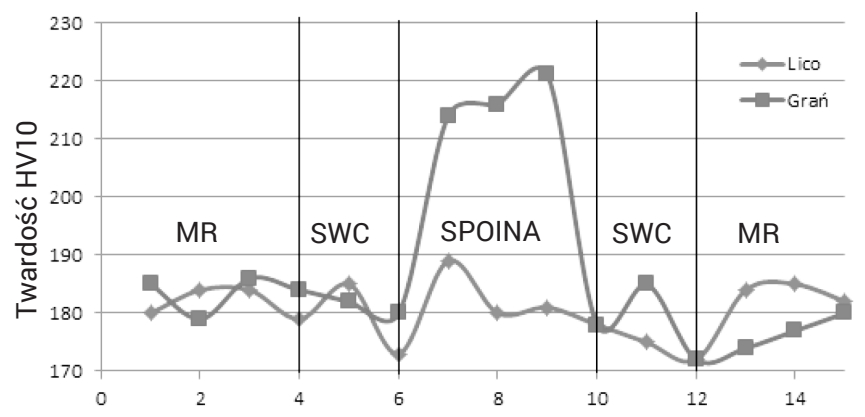

Rys. 1. Schemat natryskiwania naddźwiękowego [4]

Fig. 1. Scheme of supersonic spraying process [4]

Tablica III. Skład chemiczny, właściwości mechaniczne oraz parametry pracy elektrody FOX A7 [1]

Table III. Chemical composition and welding parameters of FOX A7 electrode [1]

\begin{tabular}{|c|c|c|c|c|}
\hline \multicolumn{5}{|c|}{ Zawartość pierwiastków, \% masy } \\
\hline C & $\mathrm{Si}$ & $\mathrm{Mn}$ & $\mathrm{Cr}$ & $\mathrm{Ni}$ \\
\hline 0,1 & 0,7 & 6,5 & 18,8 & 8,8 \\
\hline \multicolumn{4}{|c|}{ Właściwości mechaniczne } & $\begin{array}{l}\text { Parametry } \\
\text { pracy }\end{array}$ \\
\hline $\begin{array}{l}\mathrm{Re}_{\mathrm{e}} \\
\mathrm{MPa}\end{array}$ & $\begin{array}{l}\mathrm{R}_{\mathrm{m}} \\
\mathrm{MPa}\end{array}$ & $\begin{array}{l}\mathrm{A}, \\
\%\end{array}$ & $\begin{array}{c}\mathrm{KV}, \\
\mathrm{J}\end{array}$ & $\begin{array}{c}\text { Temperatura } \\
\text { pracy }\end{array}$ \\
\hline 480 & 660 & 38 & 90 & do $850{ }^{\circ} \mathrm{C}$ \\
\hline
\end{tabular}




\section{Badania metalograficzne makroskopowe}

Przekrój złącza pokazany na rysunku 2 (makrostruktura złącza) nie ujawnił żadnych niezgodności w skali makro i uzyskał poziom jakości B według PN-EN ISO 5817. Spoina charakteryzuje się poprawnym kształtem geometrycznym oraz prawidłowym układem ściegów. Na zdjęciach makrostruktury można zauważyć rozrost ziaren struktury w strefie wpływu ciepła w obydwu złączach, szczególnie w obszarze CGHAZ, czyli strefie struktury przegrzanej.

\section{Badania metalograficzne mikroskopowe}

Badania mikrostruktury przeprowadzono na przygotowanych zgładach metalograficznych, trawionych odczynnikiem metalograficznym chlorkiem żelaza. Obserwację i rejestrację obrazów mikrostruktury przeprowadzono za pomocą mikroskopu świetlnego Axiovert 25 (OM).

\section{Materiał rodzimy}

Badana stal w stanie dostawy posiadała strukturę ferrytyczną z częściowo zachowaną teksturą oraz pasmowo wydzielonymi węglikami. Pasmowość wydzielonych węglików odpowiada prawdopodobnie kierunkowi przeróbki plastycznej badanego materiału. W strukturze obserwowano również pojedyncze, roztrawione, o sferoidalnym kształcie siarczki (rys. 3).

\section{SWC}

W obszarze strefy wpływu ciepła widoczne były obszary niewymieszane objawiające się jako charakterystyczne "języczki". Ich występowanie spowodowane jest obecnością podczas spawania w jeziorku nieruchomej warstwy cieczy (tzw. warstwy Nernsta), przyległej do linii wtopienia [2] - rysunek 4.

\section{SWC $w$ pobliżu linii wtopienia}

W obszarze SWC bezpośrednio przyległym do spoiny - linia wtopienia, obserwowano rozrost ziarna ferrytu w porównaniu do materiału rodzimego, po granicach ziaren ferrytu widoczne były wydzielone płytkowe węgliki, natomiast wewnątrz ziaren ferrytu ujawniono występowanie pojedynczych wydzieleń o zróżnicowanym kształcie. Wewnątrz ziaren ferrytu obserwowano ponadto budową podstruktury ferrytu - rysunek 5.

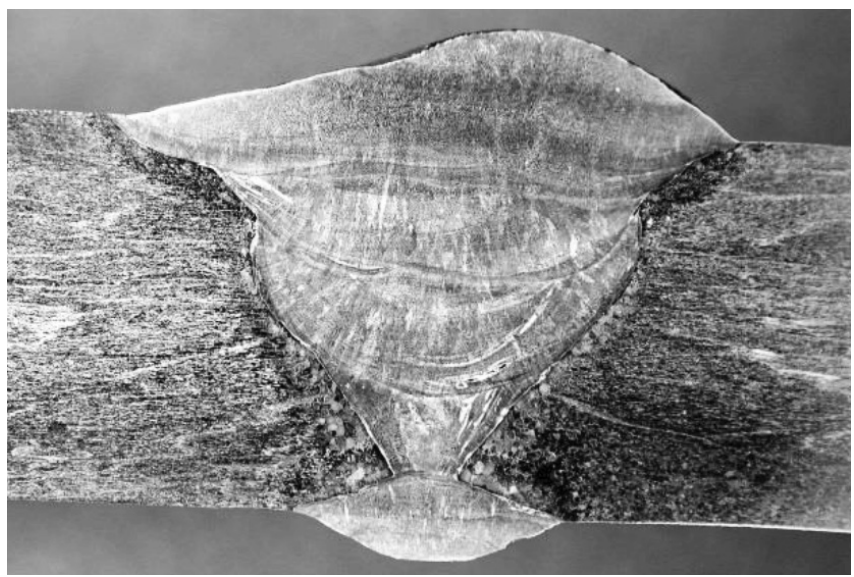

Rys. 2. Makrostruktura złącza bez podgrzewania wstępnego ze stali X10CrAlSi13 (P1). Trawiono chlorkiem żelaza [1]

Fig. 2. Macrography of X10CrAlSi13 welded join (P1) without preheat [1]

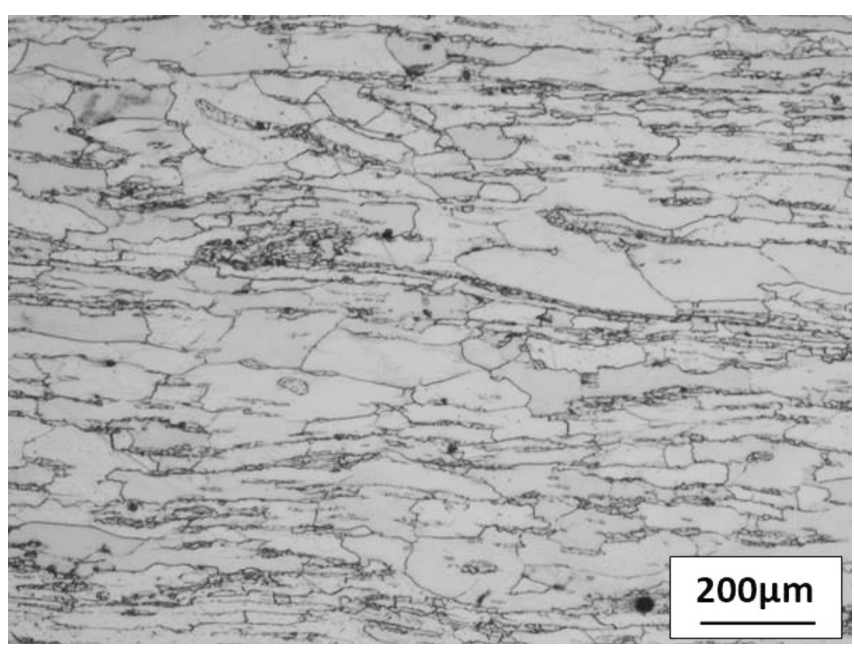

Rys. 3. Mikrostruktura materiału rodzimego

Fig. 3. Microstructure of parent material
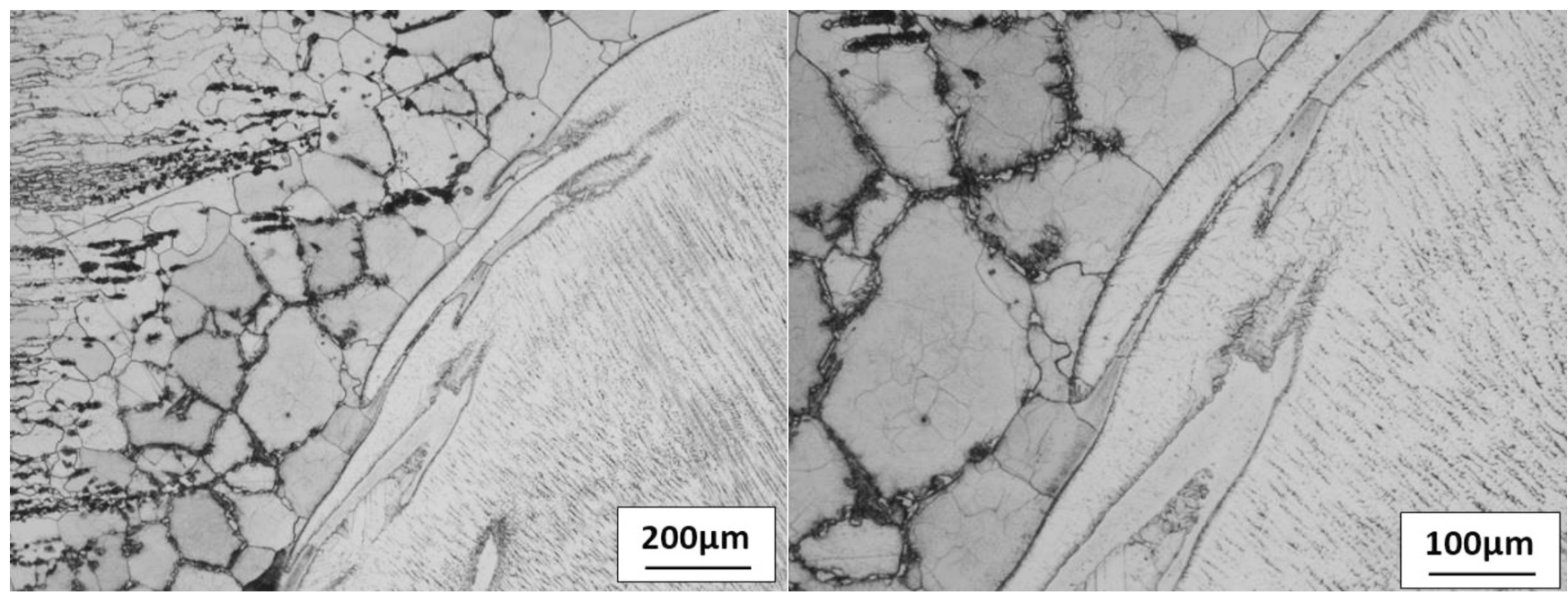

Rys. 4. Mikrostruktura SWC oraz charakterystyczne "języczki"

Fig. 4. Microstructure of HAZ and characteristic "tongues" 

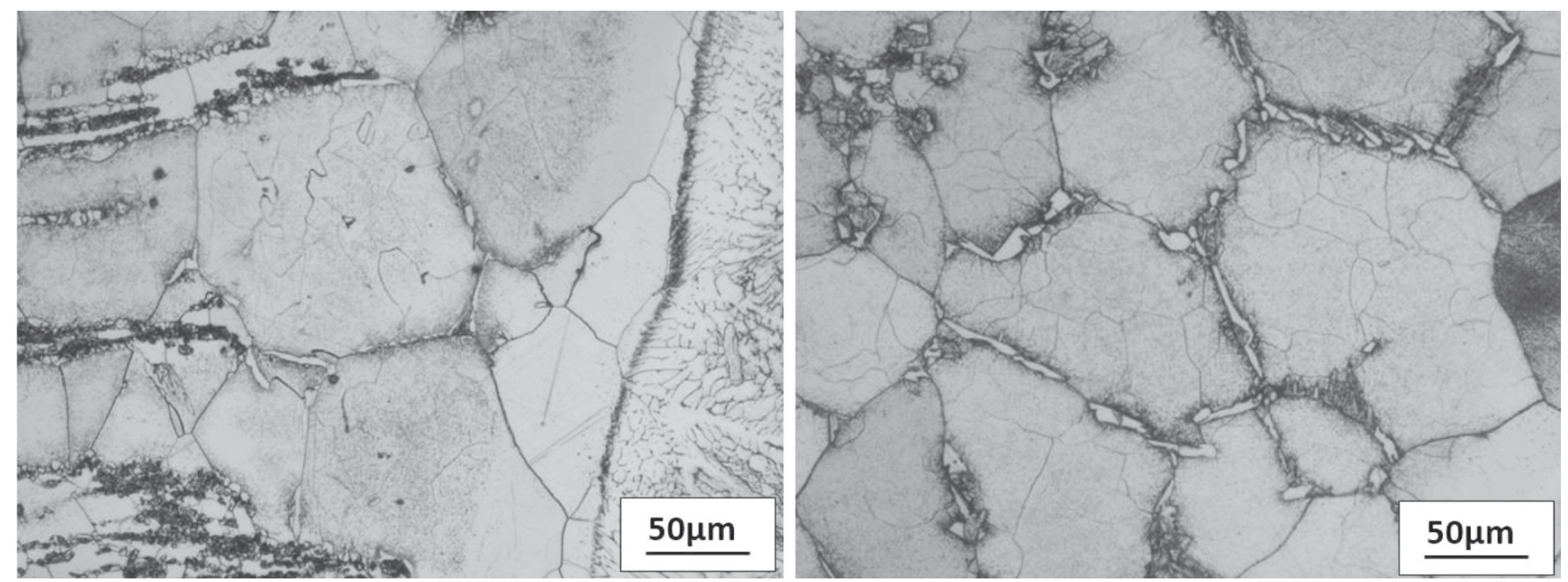

Rys. 5. Mikrostruktura w pobliżu linii wtopienia

Fig. 5. Microstructure of HAZ near fusion line

\section{Podsumowanie}

W złączu spawanym zaobserwowano wydzielenia płytkowych węglików po granicach ziaren oraz pojedyncze wydzielenia wewnątrz ziaren ferrytu. Nastąpił również rozrost ziarna ferrytu w porównaniu do materiału rodzimego pod wpływem dostarczonego ciepła w procesie spawania. W SWC również wystąpiły obszary niewymieszane spowodowane nieruchomą warstwą cieczy "warstwą nersta” przyległej do linii wtopienia. W materiale rodzimym zaobserwowano pasmowo wydzielone węgliki prawdopobodnie poprzez obróbką cieplną MR.

W związku z powyższym proces spawania w wyniku wydzieleni węglików prawdopodobnie zwiększył kruchość złącza ze stali X10CrAISi13 oraz uczulił na korozję międzykrystaliczną ze względu na zubożenie chromu w obszarze granic ziaren. Nastąpił również znaczny rozrost ziarna zazwyczaj negatywnie wpływający na właściwości mechaniczne.

Dalsze badania nad złączami spawanymi stali X10CrAlSi13 powinny obejmować zastosowanie obróbki cieplnej według zaleceń norm, na złączach bez podgrzewania i z zastosowanym podgrzewanym wstępnym.

Celowym byłyby przeprowadzenie badań metalograficznych na złączach spawanych z podgrzewaniem wstępnym oraz złączach po obróbce cieplnej w celu zaobserwowania różnic w mikrostrukturach.

Ponadto istotnym byłoby określenie wpływu zmniejszenia energii liniowej na poziomie 0,5 $\div 1 \mathrm{~kJ}$ na właściwości złącza wykonanego ze stali X10CrAISi13.

\section{Literatura}

[1] M.Woszek, J.Słania, G.Golański: Wpływ podgrzewania wstępnego na właściwości mechaniczne złączy spawanych ze stali X10CrAlSi13. Przegląd Spawalnictwa, Vol. 88, nr 5, 2016

[2] Tasak E., Ziewiec A.: Spawalność materiałów konstrukcyjnych Tom 1: Spawalność stali. Wydawnictwo JAK, Kraków 2009.

[3] Blicharski M.: Inżynieria Materiałowa stal. WNT wydanie drugie, Warszawa 2012
[4] Poradnik Inżyniera: Tom 1 Spawalnictwo, pod redakcja prof. dr. hab. inż. Jana Pilarczyka. Wydawnictwo WNT, Warszawa 2014

[5] Dobrzański L.A.: Metaloznawstwo i obróbka cieplna stopów metali. Wydawnictwo Politechniki Śląskiej, Gliwice 1993.

[6] Ferenc K.: Spawalnictwo. WNT, Warszawa 2013.

\section{Zapraszamy Państwa do odwiedzenia i polubienia naszego profilu na Facebooku}

